\title{
Construindo pontes interdisciplinares
}

\section{Constructing interdisciplinary bridges}

\author{
Thiago Rocha da Cunha \\ Doutorando, Programa de Pós-graduação em Bioética/Universidade de Brasília; bolsista, \\ Núcleo de Estudos sobre Bioética e Diplomacia em Saúde (Nethis). \\ thiagocunha@unb.br
}

\author{
José Paranaguá de Santana \\ Coordenador, Nethis. \\ jparanagua@gmail.com
}

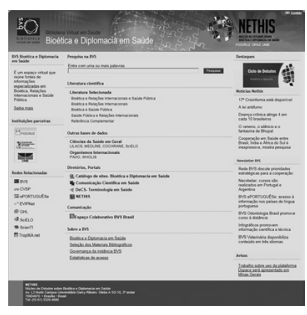

Biblioteca Virtual em Saúde Bioética e Diplomacia em Saúde http://bvsbioeticae diplomacia.fiocruz.br cooperação técnica entre países pressupõe solidariedade,
consenso e equidade em suas relações. Contudo, a desigualdade
e dependência nas relações políticas, econômicas e militares na esfera
internacional dificultam o estabelecimento de propostas genuínas
de cooperação horizontal com consequências vantajosas, resultando
frequentemente em projetos com efeitos danosos para as nações
mais pobres. A transição para o século XXI configurou um cenário
demarcado pela derrocada do projeto socialista soviético; por repetidas
crises econômicas do bloco capitalista; pela emergência de países
antes incluídos na categoria de subdesenvolvidos e que passaram a ser
designados emergentes ou de renda intermediária; pela consolidação da influência em escala global na China; e, sombreando os aspectos anteriores, a persistência dos EUA como centro mundial de poder. Nesse contexto se fortaleceram interesses entre os países em desenvolvimento, majoritariamente situados no hemisfério Sul e, no bojo desse processo, iniciativas alcunhadas de cooperação Sul-Sul. A área de saúde acompanhou a evolução histórica desses processos de cooperação entre países que aspiram a superar as condições de desigualdade e dependência e suas consequências lamentáveis no plano das condições de vida e saúde das suas populações (Santana, 2011).

Praticamente em todos os países agravam-se os problemas decorrentes do custeio dos serviços de saúde, em boa medida relacionados à incorporação de inovações tecnológicas. Também ressaltam os efeitos da transição demográfica e epidemiológica para os sistemas de saúde, bem como as transformações ambientais com efeitos sobre as condições de vida e saúde das pessoas e das coletividades. Essas características e suas projeções para o futuro refletem o paradoxal agravamento das condições de vida e saúde vis-à-vis o desenvolvimento 
econômico e técnico-científico, de forma associada às discrepâncias de riqueza e bem-estar entre diferentes partes do planeta.

Os dilemas éticos identificados nesse cenário de acelerado desenvolvimento das ciências e das suas aplicações tecnologias são objeto da bioética desde a sua consolidação, nos anos 1970. Contudo, a abordagem predominante nessa fase inicial, especialmente nos EUA, privilegiou o enfoque dessa disciplina às interações entre indivíduos, geralmente profissionais da saúde e pacientes ou, com mais ênfase, pesquisadores e pessoas envolvidas em projetos de investigação. Do ponto de vista normativo, essa abordagem valoriza os princípios do respeito à autonomia e da liberdade individual (Jonsen, 1998). Já a construção da bioética no Brasil recebeu forte influência do arcabouço doutrinário do Movimento da Reforma Sanitária (Lima, Santana, 2006), ampliando a abordagem dos dilemas éticos na perspectiva coletiva e não apenas individual, bem como suas implicações na esfera das relações do poder público para além dos interesses privados. Trata-se de uma nova abordagem, desenvolvida originalmente e compartilhada no contexto da América Latina, que valoriza princípios da equidade, proteção, vulnerabilidade e emancipação (Porto, Garrafa, 2011).

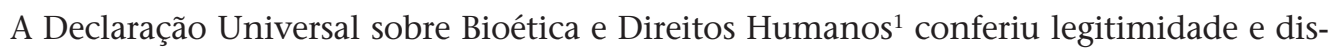
seminou a abordagem bioética construída no Brasil e na América Latina a partir dos anos 1990 (Barbosa, 2006), incluindo em seu escopo normativo a defesa da dignidade humana, o respeito ao pluralismo cultural, a cooperação internacional e outros aspectos até então insuficientemente considerados no discurso hegemônico da disciplina. O documento estabelece a responsabilidade ética dos Estados e dos atores internacionais na promoção da saúde e da qualidade de vida das populações, com especial atenção aos indivíduos e grupos dos países em desenvolvimento. Trata-se de uma renovação no campo da interdisciplinaridade, aproximando a bioética de outros campos do conhecimento como a saúde pública e as relações internacionais.

Nesse sentido, o portal web do Núcleo de Estudos sobre Bioética e Diplomacia em Saúde (Nethis) ${ }^{2}$ foi criado com o propósito de apoiar um processo colaborativo de aproximação interdisciplinar entre esses diferentes campos acadêmicos e de atividades profissionais, facilitando acesso a informações técnico-científicas dessa interface de conhecimentos mediante: a biblioteca virtual temática; a seção "Documentos de referência" sobre "Bioética e direitos humanos" e "Cooperação Sul-Sul e diplomacia em saúde"; documentos, artigos e relatórios de reuniões que constituem o rol de produtos desenvolvidos sob auspícios do referido núcleo de estudos.

A conexão para a Biblioteca Virtual sobre Bioética e Diplomacia em Saúde ${ }^{3}$ remete para as coleções de publicações nas interfaces entre bioética, relações internacionais e saúde pública, na linha de um dos objetivos da Declaração Universal sobre Bioética e Direitos Humanos, de promoção equitativa ao desenvolvimento das ciências e das tecnologias por meio do compartilhamento das informações e dos conhecimentos científicos.

No acervo de "Documentos de referência" do sítio, disponibilizam-se referências sobre bioética e direitos humanos e outras normas internacionais voltadas para a regulação ética das pesquisas envolvendo seres humanos, bem como relatórios e declarações de interesse da saúde pública no contexto das relações internacionais. Ao consultar o item "Ciclo de debates" encontram-se registros (programação, vídeos, apresentações, relatórios e sessões anteriores) 
dos encontros promovidos pelo Nethis, reunindo especialistas dos diferentes campos de investigação. A seção "Videoteca" dá acesso a vídeos institucionais, aulas ministradas em cursos promovidos pelo Núcleo, palestras e entrevistas realizadas com especialistas das áreas de interface.

No menu "Cursos" encontram-se os documentos referentes às iniciativas de ensino, como os relatórios, conteúdos programáticos, corpo docente, recursos didáticos, referências bibliográficas, cronogramas e apresentações dos professores. E em "Notícias" apresentamse destaques e informações sobre eventos e iniciativas do Nethis e de instituições que progressivamente se constituem numa rede de relacionamento em torno dos temas em tela.

Esse portal na internet é mantido pelo referido núcleo de estudos, uma iniciativa interinstitucional da Fundação Oswaldo Cruz, por intermédio do Centro de Relações Internacionais; da Universidade de Brasília, mediante a Cátedra Unesco e o Programa de Pós-graduação em Bioética, que conta com apoio da Organização Pan-americana da Saúde, por meio de sua representação no Brasil.

\section{NOTAS}

${ }^{1}$ Declaração aprovada por aclamação na 33a sessão da Conferência Geral da Unesco em 19 de outubro de 2005.

${ }^{2}$ http://www.bioeticaediplomacia.org.br

${ }^{3}$ http://www.bioeticaediplomacia.bvs.br

\section{REFERÊNCIAS}

BARBOSA, Swedenberger.

A participação brasileira na construção da Declaração Universal sobre Bioética e Direitos

Humanos da Unesco. Revista Brasileira de Bioética, v.2, n.4, p.412-418. 2006.

JOSEN, Albert.

The birth of bioethics. New York: Oxford

University Press. 1998.

LIMA, Nísia Trindade; SANTANA, José Paranaguá

de.

Saúde coletiva como compromisso: a trajetória da

Abrasco. Rio de Janeiro: Fiocruz; Abrasco. 2006.
PORTO, Dora; GARRAFA, Volnei.

A influência da reforma sanitária na construção das bioéticas brasileiras. Ciência e Saúde Coletiva, v.16, supl.1, p.719-729. 2011.

SANTANA, José de Paranaguá de.

Um olhar sobre a cooperação Sul-Sul em saúde. Ciência e Saúde Coletiva, v.16, n.2, p.2415-2424. 2011. 